\title{
“MONTAÇ̃̃O, TOMBAÇ̃̃O, PICUMÃ̄": UMA ANÁLISE ANTROPOLÓGICA DA PERFORMANCE DRAG EM CAMPO GRANDE - MS ${ }^{1}$
}

\author{
"MONTAÇÃO, TOMBACÃO, PICUMÃ": AN ANALYSIS ANTHROPOLOGICAL OF THE PERFORMANCE DRAG IN \\ CAMPOGRANDE - MS
}

\section{RESUMO}

Este artigo objetiva analisar a configuração da performance drag diante de uma sociedade que regula corpos de acordo com suas normas. Isso é feito a partir da compreensão da experiência das participantes do concurso "Corrida das Drags", na cidade de Campo Grande, estado de Mato Grosso do Sul. O referencial teórico adotado é dos estudos subalternos. Através do levantamento bibliográfico, da etnografia realizada durante as apresentações, das entrevistas com os interpretes das drags, conclui-se: a) há agência nas performances drag, a partir do desejo de se montar, que carrega significações e pode reiterar ou não as normas sociais; b) a "matéria prima” desta agência são seus corpos, pois são neles que ocorrem as intersecções mediadas sócio-culturalmente, c) diferentemente do que a teoria da performatividade butleriana apontou em outros contextos e período, nesse estudo observou-se que as drags têm como referencial não somente a mulher, mas outras drags.

Palavras chave: Drag queen. Corpos. Performance. Diferenças. Agência. Normas.

\section{ABSTRACT}

This article aims to analyze the drag performance configuration in a society that regulates bodies according to standard norms. This is done by understanding the experience of the contestants at "Corrida das Drags", in the city of Campo Grande, in the state of Mato Grosso do Sul. The theoretical framework adopted comes from the subaltern studies. Through the bibliographic survey and the ethnography performed during the presentations, followed by interviews with the interpreters of the drags, we conclude: a) there is agency in drag performances, based on the desire to assemble, which carries meanings and may or may not reiterate social norms; b) the "feedstock" of this agency is their bodies, because the socio-culturally mediated intersections occur thourgh them; c) unlike what the Butlerian performativity theory pointed out in other contexts and periods, in this study it was observed that the drags have as a

1 A escolha do título refere-se à linguagem usada pelas drag queens: "montação" - termo para designar o ato de montar-se; "tombação" - atitude poderosa ou quando alguma delas vai muito bem em alguma apresentação; "picumã" - peruca.

Winny Gabriela Santana

Programa de Pós-graduação em Antropologia Social. Universidade Federal de Mato Grosso do Sul Brasil.winnysantana82@gmail.com

Tiago Duque

Professor Doutor do Programa de Pós- graduação em Antropologia Social e Programa de Educação do campus Pantanal- Universidade Federal de Mato Grosso do Sul - Brasil. duque_hua@yahoo.com.br 
reference not only woman, but other drags.

Keywords: Drag queen. Bodies. Performance. Differences. Agency. Norms.

\section{Introdução}

As drags queens tem ganhado visibilidade nas últimas décadas em diferentes partes do mundo, e não exclusivamente em contextos de sociabilidade gay e lésbico. Mas, mesmo nesses contextos, considerando a própria dinâmica históricosociocultural, a performance que executam podem nos apresentar novas questões sobre gênero e sexualidade. Nesse sentido, este artigo tem como objetivo analisar a configuração da performance drag diante de uma sociedade que regula corpos de acordo com suas normas. Isso é possível a partir da análise da experiência das participantes do concurso "Corrida das Drags", na cidade de Campo Grande, estado de Mato Grosso do Sul.

Em um dos lugares da cena alternativa da cidade, em uma noite marcada pela presença de artistas drags, algumas pessoas se apertavam para assistir à abertura da quarta edição do referido concurso, com a primeira apresentação baseada no videoclipe da música Sua Cara, de Anitta e Pablo Vittar². Após a apresentação, o discurso da apresentadora do evento foi em tom de denúncia do espaço artístico permitido a elas: "queríamos o Glauce Rocha, mas estamos aqui no Resista".

O Glauce Rocha é um teatro de muito prestígio no estado, localizado na Universidade Federal de Mato Grosso do Sul, contendo 821 lugares e que existe há aproximadamente 50 anos $^{3}$. No entanto, o Resista Bar, onde ocorreu o evento (no momento do trabalho etnográfico), situava-se na Av. Calógeras, em uma região menos valorizada do centro da cidade. Foi inaugurado em setembro de 2017 e fechado em fevereiro de 2019. A ideia era ter um espaço para atender as demandas de um público que estava saturado do cenário musical ${ }^{4}$ campo-grandense, deste modo, era possível ver muitos elementos ditos "alternativos", como cartazes, grafites, bancos feitos de latas, uma parede de fitas cassete que servia para os clientes como um painel para tirar fotos, entre outros. Em sua página no Facebook, afirma-se que o bar surgiu "com a proposta de abrir espaço para a contracultura", e prossegue: "O

2 Anitta é cantora do cenário pop mundial e Pablo Vittar é uma cantora pop drag queen famosa no Brasil. O videoclipe "Sua cara" pode ser assistido em: www.youtube.com/results?search_query=sua+cara Acesso em: o6 de maio de 2019.

3 Mais informações disponíveis em: https://www.ufms.br/teatro-glauce-rocha-e-cenario-historico-degrandes-espetaculos-do-ms/ Acesso em: 22 de abr. 2019.

4 A cidade de Campo Grande possui um ambiente cultural marcado predominantemente pelas culturas gaúchas, paraguaias e caipiras, o que acabou por definir a predominância do estilo musical sertanejo. Disponível em: https://www.ufms.br/academicos-de-musica-mapeiam-generos-musicais-popularesde-ms/ Acessado em 11 de nov. de 2018. 
lema é resistência, seja fazendo música, teatro, poesia ou apresentações audiovisuais, queremos movimentar o cenário de mentes inquietas e criativas". ${ }^{5}$

Mesmo neste espaço menos prestigiado e reconhecido, contrastando com o teatro Glauce Rocha por exemplo, a "Corrida das Drags" inaugura um "marco de representatividade". De acordo com as falas de alguns espectadores que estavam ali, aquele evento representava uma alternativa para o movimento underground da cidade. Assim, o focaremos aqui por sua relevância no cenário de um estado do Centro-Oeste brasileiro, mas também pelo o que a sua análise pode contribuir para a reflexão em torno de uma nova geração de drags, isto é, para o que entendemos em relação à geração, sexualidade, gênero e região.

Esta pesquisa apresenta uma abordagem qualitativa e se desenvolveu em três etapas. Inicialmente, foi realizado um levantamento bibliográfico sobre a temática geral: gênero, sexualidade, performances e drag queens. Em seguida, foi feita a busca em mídias sociais do evento: no canal do YouTube e no perfil do Facebook, a fim de acessar esse universo artístico. Após essa etapa, foi realizada a etnografia no Resista Bar, no intuito de (re)conhecer e se aproximar das interlocutoras e interlocutores. Por fim, em um terceiro momento, foram realizadas as entrevistas, com um roteiro pré-definido, com seis interlocutoras, sendo cinco participantes e uma organizadora do evento.

\section{A Corrida das Drag}

A nossa escolha etnográfica por um concurso de drags sul-mato-grossenses se deu a partir da observação prévia da realidade local, tanto em ambiente online como offline, no que se refere a esse tipo de performance, afinal, o concurso reúne uma nova geração de drags, ou aspirantes a drag, que apostamos que poderiam nos apresentar o que tem de mais novo nessa experiência performática. A opção por frequentar o local do concurso enquanto ele se realizava está fundamentada pelo o que entendemos como etnografia, isto é, "como uma forma especial de operar em que o pesquisador entra em contato com o universo dos pesquisados e compartilha seu horizonte" (Magnani, 2009: 135), mas não apenas isso, afinal, não entramos em contato com as drags, o público do evento, os jurados e juradas

para permanecer lá ou mesmo para atestar a lógica de sua visão de mundo, mas para, seguindo-os até onde seja possível, numa verdadeira relação de troca, comparar suas próprias teorias com as deles e assim tentar sair com um modelo novo de entendimento ou, ao menos, com uma pista nova, não prevista anteriormente (Magnani, 2009: 135)

5 Mais informações disponíveis em: https://www.facebook.com/resistabar/?epa=SEARCH_BOX Acesso em: or de jun. de 2019. 
O evento foi pensado, segundo Paloma ${ }^{6}$, uma das organizadoras que entrevistamos, a partir de uma conversa entre amigos, que tinha a intenção de fazer a exibição do reality show Rupaul's Drag $\operatorname{Race}^{7}$ em bares da cidade, visto que é um programa norte-americano com transmissão restrita, e que capta grande audiência do público diversificado entre gays, lésbicas, héteros e trans . No entanto, com o intuito de apresentar algo além da exibição do seriado, as organizadoras e organizadores do evento pensaram em, concomitantemente à exibição dos episódios, dar espaço a performances de novas drags da região. A influência do reality pode ser vista desde o formato do evento até o seu nome, uma tradução literal de Drag Race. Paloma afirmou ainda que esse evento foi muito bom para a casa, pois o objetivo do bar, como dito anteriormente, era apoiar o cenário underground da cidade.

Ressalta-se que em Campo Grande existem, aproximadamente, cinco ambientes de apresentação/shows ${ }^{8}$ de drags. Assim, é possível identificar um aumento recente na publicidade dos eventos (publicação nos jornais on-line Midiamax, Campo Grande News e Capital News). Nesses espaços, as apresentações comumente são de drags profissionais, isto é, há mais tempo desenvolvendo as apresentações e recebendo um cachê para fazê-las. Frequentemente, esses ambientes não abrem espaço para que novas drags da cidade se apresentem. Ainda sobre os lugares, a diversidade desses espaços está demarcada pelo perfil de público, sendo alguns frequentados por pessoas mais jovens e outras menos jovens, além do fato de serem demarcados por cor, gênero e classe, sendo que alguns têm um públicos mais feminino que outros ou, por sua vez, alguns com público de classe econômica mais baixa, e também de pele mais escura, se comparado com outros.

Em relação ao histórico de realização do evento "Corrida das drags", a primeira, segunda e terceira edição ocorreram respectivamente no Bar da Valu ${ }^{9}$ (março de 2016); no Drama Bar ${ }^{10}$ (setembro de 2016) e no Sis Lounge ${ }^{11}$ (abril de 2017),

6 Para a preservação das identidades das interlocutoras e interlocutores, todos serão nomeados aqui por nomes fictícios.

7 RuPaul's Drag Race é uma série de televisão que documenta a busca da mais famosa das drag queens pela "próxima estrela drag dos EUA". A icônica RuPaul vem desfrutando de sucesso global desde os anos 1990 com programas de televisão, participações no cinema e vários álbuns lançados, mas foi sua capacidade de criar conexões entre os públicos LGBT e simpatizantes que a catapultou para o status de entidade midiática. Disponível em: https://www.cartacapital.com.br/sociedade/uma-reflexao-sobrerupaul2019s-drag-race. Acesso em: 13 de out. 2018.

8 Ressalto que considero shows, assim como Vencato (2002), qualquer atividade desenvolvida nos palcos, o que engloba dublagem, danças, teatros, diálogos e premiações.

9 O bar Valu está localizado na rua Treze de maio, responsável pelo bloquinho de carnaval de rua Cordão da Valu. Em sua página no Facebook, é possível constatar que é um bar com estilo musical samba.

1o O Drama Bar era um local conhecido pela sua "diversidade". tinha como proposta, conforme a mensagem em sua página no Facebook, "Valorizar a cena artística da nossa região, promover encontros inusitados com atrações quentes, criar novas formas de se expressar, de se divertir, de gozar a vida e dramatizar mais que novela mexicana".

11 O Sis Lounge é uma boate LGBT, conhecida por oferecer shows drag todas as sextas e sábados, além de festas temáticas com hostess drag. Conforme em sua página no Facebook, "O SIS Lounge apresenta-se como um espaço de encontro, valorização, respeito e empoderamento da diversidade. Idealizado para 
e consistiram na transmissão dos episódios do reality show RulPaul's Drag Race, juntamente com oficinas de dança e montagem, bazares, e algumas apresentações sem caráter competitivo - o que as diferem da quarta edição. Esses lugares têm em comum o fato de seu público, com exceção do Bar Valu, ser quase majoritariamente LGBT, ainda que a presença de LGBT também possa existir esporadicamente no Valu. Ou seja, o evento aconteceu em lugares estratégicos para envolver um público LGBT.

No decorrer desta pesquisa, foram entrevistadas pessoas envolvidas na última edição, que ocorreu no Resista Bar. Paloma, a única mulher transexual das entrevistadas e uma das organizadoras do evento, tem 31 anos, branca e experiência de arte drag. As demais são todas homens gays não-trans : Trufada do Vrá, 25 anos, drag há 5 anos, negra e a única gorda; Katy James, 21 anos, drag há um ano, se considera parda; Estrela da Luz, 25 anos, branca, drag há 3 anos; Rainbow, 22 anos, há dois anos fazendo arte drag, negra; e Stela Pink, 24 anos, há dois anos fazendo arte drag, branca.

A edição da "Corrida das drag" analisada neste artigo foi a primeira com um caráter competitivo. Participaram seis drags concorrentes ao prêmio de, segundo Paloma,

uma peruca em primeiro lugar, uma front-lace, que é aquela que tem na frente uma redinha que parece cabelo humano, cabelo de verdade, e um kit de pincéis. E uma peruca long bob para o segundo lugar, que não é front-lace. (Transcrição de entrevista realizada com Paloma em 13/og/2018)

Além disso, de acordo com a interlocutora, foi concedido à vencedora um contrato de trabalho nas boates que patrocinaram o evento. O critério de escolha das participantes foi feito por um edital que exigia uma série de requisitos:

[...] como a corrida das drags é um concurso, um evento drag, de shows drag, a gente não queria uma pessoa só pela beleza, né? E a gente pediu para que as drags mandassem vídeos, mesmo desmontada, tipo de boy mesmo, dublando uma música de até 30 segundos. O vídeo só para a gente ver mesmo a dublagem, a expressão facial, se ela ia usar alguma coisa, se ia brincar né? (Transcrição de entrevista realizada com Paloma em 13/o9/2018)

Katy James, a ganhadora da Corrida das Drag, foi vista pelas outras candidatas durante a competição como a menos ameaçadora, pois ela era nova, começou a se apresentar ali no evento, e se montava há pouco tempo. Quando ela ganhou, muitos ficaram surpresos, pois, afinal, a disputa se deu entre ela e Estrela da Luz, uma drag

oferecer noites divertidas e inesquecíveis, com conforto, bom atendimento e qualidade. O Lounge, há 8 anos atua na noite campo-grandense trazendo entretenimento, arte, diversão e boa música. Atuamos de forma profissional, cuidando de cada detalhe para oferecer experiências felizes e confortáveis com entretenimento de alto padrão”. 
que já se montava há 3 anos. Muitos ali disseram que foi por causa da dublagem. Devido ao espanto das competidoras com o resultado do concurso, fora pensado quais seriam os critérios de avaliação. Ao ser questionada sobre isto, Paloma respondeu:

era dividido por quesitos né? Aí tinha maquiagem, figurino, presença de palco, conceito da performance, carisma. Enfim, eu não lembro de todos os quesitos, mas a gente tinha normalmente três jurados que eram da corrida e normalmente um jurado convidado. [...] chamamos essas pessoas, que são conhecidas na noite, e aí os jurados davam uma pontuação de cinco a dez. E, no final, depois da última apresentação, nós chegamos nas três finalistas, que era a Katy James, Estrela da Luz e Stela Pink. Aí, na final que tinha os shows delas, os jurados convidados decidiram top 2. Aí as duas finalistas teriam que dublar, fazer uma dublagem pela medalha, que a gente brincou que não é uma coroa, como é uma corrida, elas iam ganhar uma medalha. (Transcrição de entrevista realizada com Paloma em 13/o9/2018).

Durante a entrevista com Trufada do Vrá, uma associação chamou atenção por demarcar os espaços e os eventos que são ditos como importantes para um suposto binarismo hétero/homo. Em suas palavras:

\begin{abstract}
A "Corrida das drags" para mim é um futebol dos héteros, vamos se dizer assim, a "Corrida das drag" para mim está crescendo na cultura, está acrescentando arte em você, está vendo a mana fazendo ali um show que você não tem o hábito de fazer, você está ali, está enaltecendo a arte drag. É o que eu vivo, é o que eu gosto, aquilo lá para mim é um futebol. Aí você está vendo RuPaul's ali, que é uma inspiração, é uma baita de uma mulher. Você fica louca com a situação ali. Aí quando eu fiquei sabendo das inscrições para a corrida, eu fiquei louca, bora participar... (Transcrição da entrevista realizada com Trufada do Vrá em 13/ o8/ 2018).
\end{abstract}

As apresentações foram realizadas durante os meses de fevereiro e março de 2018, aos sábados à noite. Todas as apresentações foram gravadas e disponibilizadas no canal do evento na plataforma Youtube e na página do Facebook pela organização. As montagens das drag queens foram gravadas e inseridas no canal dentro do quadro "Desaquendadas". Esse aspecto é muito próximo ao formato do reality show RuPaul's Drag Race, onde a montagem das drags é filmada e inserida dentro dos quadros semanais das apresentações performáticas das participantes. Longe de ser apenas um detalhe, no evento o ato de montar-se representa uma parte fundamental à compreensão artística da performance.

Portanto, pode-se dizer, a partir de dados de campo e das falas das interlocutoras, que a montagem seria um ato de criar a sua personagem, não apenas 
com maquiagem, mas também com o nome da sua drag, o comportamento, as performances, produzindo assim uma personagem com características próprias. $\mathrm{O}$ montar da drag, no caso de Katy James, se caracteriza desde o momento em que ela passa o batom, ou, no caso de Rainbow, quando coloca a peruca, até o momento em que sobe no palco e se porta diferentemente de quando se está desmontada. Discutiremos essas experiências a seguir, considerando que quem experimentou participar do concurso, enquanto sujeito, não é um "sujeito da experiência” já plenamente constituído a quem as "experiências acontecem", pelo contrário, a experiência é o lugar da formação do sujeito (BRAH, 2006).

\section{A arte drag e as questões identitárias}

Algumas autoras e autores, quando diferenciam as drags, apontam uma problemática da configuração da identidade sexual do grupo. Maria Teresa Vargas Chidiac e Leandro Castro Oltramari associam o ser drag ao trabalho artístico, pois há a elaboração de uma personagem: "A elaboração caricata e luxuosa de um corpo feminino é expressa através de artes performáticas como a dança, a dublagem e a encenação de pequenas peças" (2004: 471). Ainda afirmam que as drags atuam sob um conceito mais flexível de travestismo e que, embora elas sejam atores transformistas, distingue-se das travestis por andarem, em seu cotidiano, "vestidos de homem", exercendo também profissões diversas, não afeitas ao transformismo durante o dia.

Refletindo sobre essa diferenciação desses corpos, as drags que participaram do estudo fizeram questão, sem terem sido questionadas sobre isso nas entrevistas, de ressaltar que "drag não é travesti", pois normalmente a sociedade tende a confundi-las. Essa negação se dá pelo estigma que essa identidade carrega na sociedade, denunciando os espaços que as travestis estão ocupando há algum tempo (Silva, 1993), ainda que isso tenha mudado com as gerações mais novas (Duque, 2011), espaços esses considerados marginalizados, como, por exemplo, os vinculados à prostituição. Isso é relevante para entender a tensão entre essas duas identidades e, por conseguinte, as formas delas serem diferenciadas. Em relação a isso, Katy James, considerando as pessoas que conviviam com ela em situações cotidianas, como, por exemplo, familiares e pessoas do trabalho, diz:

Bom, para eles é travesti, a maioria fala que é travesti, muitos tem essa, essa fraca visão de que se um homem se veste de mulher é para fazer programa. Então eu tenho muitos conhecidos e parentes que realmente pensam isso. Mas também têm muitos que me ajudam, que me apoiam, me incentivam, que apreciam o meu trabalho como artista e muitos fazem de tudo para me ajudar com isso. (Transcrição de entrevista realizada com Katy James em 22/06/2018.) 
Em algumas falas de Katy James, ela conta como o fato de associá-la à travestis a incomoda, pois se vê constantemente em situações que precisa negar uma identidade, no caso a travesti, para reafirmar a que considera sua, a de drag. Para ela, drag é uma manifestação artística. A ideia de arte drag é também citada por outras interlocutoras para a caracterização da diferença entre drag e travesti. Por exemplo, quando a Rainbow foi questionada sobre o que representava a arte drag, ela afirmou:

Olha são opiniões bastante diversificadas, tipo quem não é desconstruído acha que a gente está fazendo palhaçada, se montando, se travecando, se travestindo para se vender na rua, sabe? Quem não entende, mas para as pessoas que são entendidas, acham bem legal e acho que valorizam, eu acho. (Transcrição de entrevista realizada com Rainbow em 17/08/2018)

Assim, parece que a questão identitária drag tem relação a um fazer artístico, e não necessariamente a um corpo, mas, um fazer em oposição à prostituição. Esse fazer faz com que a nova geração de drags, inclusive, também possa ser composta por travesti e mulheres não-trans, o que era pouco comum em gerações anteriores, ainda que, mesmo sem se referir à drag, o "ser travesti" também tivesse vinculado aos palcos e shows de dublagem (Green, 200o; Trevisan, 2004).

Deste modo, para pensarmos em arte drag, em especial quando praticada por esses homens interlocutores, é preciso entendê-la marcada por corporalidade, temporalidade e teatralidade específicas. Referimo-nos a:

[...] temporalidade porque a drag tem um tempo "montada", outro "desmontada" e, ainda aquele em que "se monta". Diferente de travestis e transexuais, as mudanças no corpo são feitas de modo geral, com truques e maquiagem. A corporalidade drag é marcada pela teatralidade, perspectiva que é importante para compreender esses sujeitos (Vencato, 2003: 196).

Em termos de temporalidade, em uma das entrevistas realizadas no evento, transmitida no canal próprio do YouTube, a entrevistada compara a drag com produto perecível, dizendo que devemos consumir entre quatro horas, porque quando chega às cinco horas da manhã, já acabou. No trabalho de campo, observou-se que a temporalidade da drag está no ato de se montar. Elas valorizam uma maquiagem bem-feita, um figurino bem produzido, uma boa "andada em cima do salto", tudo isso para compor uma boa drag. Por exemplo, Trufada do Vrá afirma que fica "horas e horas" se montando, gastando com figurinos que ela usa apenas por uma noite.

Nas entrevistas, as interlocutoras contaram como elas se esforçaram, do ponto de vista econômico, para produzir essa montagem. A própria Trufada do Vrá menciona também que fez curso de automaquiagem, pois ela gastava muito pagando maquiador em todas as suas apresentações. Katy James também expõe 
sua preocupação acerca disso, afirmando que, como faz a arte drag, recentemente recebeu ajuda da sua família' ${ }^{12}$ na questão de maquiagem, figurinos, entre outros adornos que compõem a sua mala. Inclusive, podemos afirmar que o aparato para a montagem das drags se designa por aquilo que se carrega na mala (Vencato, 2005). Assim, a drag no olhar delas tem hora para acabar, ficando apenas por um tempo determinado montadas.

$\mathrm{O}$ aspecto da teatralidade foi observado na entrevista com a interlocutora Estrela da Luz. Ela menciona que a principal motivação para se tornar uma drag queen foi a busca pelo status de diva e dos aplausos do público. Esses elementos foram alcançados por meio da forma como ela se porta diante de quem a prestigia, que reconhece nela uma manifestação de arte. Isso pode ser visto em como ela se porta diante de seus fãs e como eles a tratam. Durante a sua apresentação, foi chamada de "diva" pelos espectadores, foi ovacionada. Era conhecida como a maior concorrente entre as competidoras.

Percebemos, assim, que elas aguçam o público com os seus comportamentos que partem do não-verbal performatizado, o gênero que "imita”. Fazem isso por meio de atos que, para Butler (200o), não são um "ato" singular ou deliberado, mas uma prática reiterativa e citacional pela qual o discurso produz os efeitos que nomeia, ou seja, não como o ato pelo qual o sujeito traz à existência aquilo que ele nomeia, mas, ao invés disso, como aquele poder reiterativo do discurso para produzir os fenômenos que ele regula e constrange. Isto é, esse ato é construído socialmente.

Nesse sentido, para Butler (1990), a performance drag brinca com a distinção entre anatomia do performista e o gênero que está sendo performado. Dessa forma, a performance drag é usada para explicar a performance que todos realizam, sendo ela totalmente construída a partir de um gênero que "queremos", buscamos.

Uma manifestação marcante da distinção entre a anatomia do performista e o gênero performado ocorre na apresentação da Rainbow, a drag barbada. Essa distinção se torna muito clara ao observar que, mesmo mantendo um elemento essencialmente masculino, como a barba, ela ainda assim satiriza o gênero feminino. Ela reconhece que, quando usa a barba em seus shows, pigmentando-a muitas vezes com lápis ou sombras de olhos, ela recebe um feedback muito legal de seus espectadores, sendo muitas vezes caracterizada como diferente das outras drags.

Butler (1990), referencia esta performatividade à paródia de gênero. Segundo Richard Miskolci e Larissa Pelúcio, essa analogia que a autora faz com a performatividade drag é uma estratégia científica.

No caso da performatividade, a paródia serve como analogia explicativa do caráter repetitivo que dá materialidade e substância (matéria) às normas de gênero. A repetição cômica das normas desnaturaliza-as e subverte-as (Miskolci \& Pelúcio, 2007: 261). 12 A família que é mencionada aqui é a família drag: quando a drag queen começa a se apresentar ela é
"apadrinhada” por alguma drag queen que tem um tempo maior de arte. 
Butler (1990), ao caracterizar essa performatividade, afirma que, na verdade, estamos na presença de três dimensões contingentes de corporeidade significante: sexo anatômico, identidade de gênero e performance de gênero. Ela explica que, se a anatomia do performista é distinta de seu gênero, e se os dois se distinguem do gênero da performance, então a performance sugere uma dissonância não só entre "sexo"13 e performance, mas entre "sexo" e gênero, e entre gênero e performance. Deste modo, a drag imita o gênero, pois, por mais que criem uma imagem de "mulher" unificada, há uma revelação da distinção dos aspectos de gênero que são falsamente naturalizados como uma unidade da ficção reguladora. Dito de outro modo:

Ao imitar o gênero, o drag revela implicitamente a estrutura imitativa do próprio gênero - assim como sua contingência. Aliás, parte do prazer, da vertigem da performance, está no reconhecimento da contingência radical da relação entre sexo e gênero diante das configurações culturais de unidades causais que normalmente são supostas naturais e necessárias. No lugar da lei da coerência heterossexual vemos o sexo e gênero desnaturalizados por meio de uma performance que confessa sua distinção e dramatiza o mecanismo cultural da sua unidade fabricada (Butler, 2003: 196-197).

O que entendemos dessa imitação de gênero é que a drag repete aquilo que é considerado normal, ou original. E isso, nesses termos, por conseguinte, não existe, pois a "mulher" que ela imita, também imita uma fantasia repetidamente. Mas, hoje, essa experiência se tornou mais complexa. Isso fica evidente na performance de uma das apresentações de abertura do concurso aqui em questão, em que a drag representa a cantora Pablo Vittar, o que evidencia uma imitação da imitação da imitação, isto é, uma drag imitando outra, que por sua vez imita a mulher que imita a norma do que é o ser feminina (idealizada como natural). Nesse sentido, a provocação decolonial de Pelúcio (2012: 413), faz todo sentido: "Nossa drag, por exemplo, não é a mesma do capítulo 3 do Problemas de Gênero de Judith Butler (2003)".

Vittar é uma drag que representa um padrão de beleza valorizado, mas também definitivamente/fixamente inatingível, de mulher, uma vez que a cantora se monta dentro de um corpo "passável" de mulher feminina não-trans, magra, hétero e branca, ou seja, a artista Pablo Vittar, comumente, constrói um corpo com elementos que levam o público a enxergar a mulher com os elementos femininos padronizados e desejados.

O termo êmico proposto como "passabilidade", diz respeito à performances contemporâneas de feminilidades e masculinidades que revelam normas e convenções constitutivas de um regime de visibilidade/conhecimento. O corpo "passável”, por exemplo, é a própria construção de uma verdade sobre o sexo e o gênero em contextos de classe, idade, cor/raça e sexualidade muito bem definidos (Duque, 2017). Assim,

13 sexo biológico. 
essa identidade de gênero que está sendo moldada se dá a partir de uma imitação sem origem. Isso acontece pelo fato de a identidade ser construída socialmente a partir de um conjunto de práticas imitativas de outras imitações (Butler, 2003).

Entendemos que as construções das identidades, portanto, estão ligadas diretamente a questões de experiência, subjetividade e relações sociais, e que, de acordo com Avtar Brah (2006), essas identidades são inscritas através de experiências culturalmente construídas em relações sociais. Logo, podemos pensar a questão da identidade como uma agência que o indivíduo realiza consciente ou não, com base no social.

A subjetividade - o lugar do processo de dar sentido a nossas relações com o mundo - éa modalidade em que a natureza precária e contraditória do sujeito-em-processo ganha significado ou é experimentada como identidade. As identidades são marcadas pela multiplicidade de posições de sujeito que constituem o sujeito. [...] De fato, a identidade pode ser entendida como o próprio processo pelo qual a multiplicidade, contradição e instabilidade da subjetividade é significada como tendo coerência, continuidade, estabilidade; como tendo um núcleo - um núcleo em constante mudança, mas de qualquer maneira um núcleo que a qualquer momento é enunciado como o "eu" (Brah, 2006: 371).

Então, esta identidade se daria por meio da agência, das possibilidades no que se refere à capacidade de agir, mediada cultural e socialmente (Piscitelli, 20o8), pois a constituição do sujeito é resultado das relações de poder no interior dos processos de interação social. O processo de subordinação, sendo ele um processo de incorporação das normas sociais, não apenas constitui o sujeito, mas possibilita condição de potência, pela qual ressignificam suas práticas e experiências (Furlin, 2013). A concepção de um sujeito reflexivo e resistente aos olhos de Butler é um sujeito performativo, sendo uma produção ritualizada das normas, mas que não o determina totalmente (Furlin, 2013).

A “matéria-prima” dessa agência se daria com as drags a partir da corporalidade, pois, segundo Vencato (2002), é nas relações que estabelece com os outros sujeitos (quem as assiste, quem as contrata, quem as admira, quem não as suporta) que a drag vai delimitando e delineando suas possibilidades de atuação, o que está muito ligada à forma como constrói sua personagem, com o produto final, mas não acabado, dessa construção.

Pode-se perceber essa questão identitária nas interlocutoras, quando definem o que o ser drag representa para si. Por exemplo, com a fala de Rainbow: "Para mim ser drag, fazer drag é o seu alter ego sabe, tipo é você mostrar na sua arte o que você não pode ser no dia a dia”. Enquanto, para Estrela da Luz, o ser ou fazer a arte drag está relacionado a um sonho realizado: 
[...] é tudo, ser drag queen é realizar um sonho de criança, ser uma diva, ser uma pessoa que eu sempre quis ser quando era criança, que era estar em cima dos palcos, as pessoas baterem palmas, é depois querendo tirar foto muitas fotos, e ver você como inspiração daquela pessoa, isso é ser drag queen para mim! É ser uma grande diva na vida das pessoas que eu não conheço, dos fans né? Porque a admiração que a gente tem deles é muito grande. Eu, desde pequeno, queria ser uma diva, mas não sabia que isso era ser drag queen quando era criança, então vem desde pequeno essa vontade (Transcrição de entrevista realizada com Estrela da Luz, no dia 11/07/2018).

O desejo de "ser diva" para Estrela da Luz ficou nítido quando durante o trabalho de campo, na etapa da entrevista, combinamos de nos encontrar no seu local de trabalho. Chegando lá, fomos para um lugar mais reservado para realizar a entrevista. Quando ela foi questionada por suas colegas de trabalho sobre do que se tratava a entrevista, ela respondeu, sem muita paciência, que se tratava de uma entrevista para o jornal Correio do Estado, que é o principal jornal diário de Mato Grosso do Sul, com 64 anos de circulação ininterrupta e credibilidade líder ${ }^{14}$. Assim, o "ser diva" está relacionado com a ideia de admiração. Afinal, ela e outras drags, estão se inspirando em cantoras (Beyoncé, Britney Spears, Katy Perry e Anitta), atrizes (Hilary Duff) e mulheres importantes na política (Hillary Clinton).

Katy James, no entanto, afirmou que o sonho de ser drag não surgiu do desejo de "ser diva”. Segundo ela,

[...] a drag começou com um hobbie, uma coisa divertida que eu fazia para me desestressar: "ah estou muito estressado essa semana, final de semana vou me montar e ir para a boate e ficar louco". Pra mim começou com isso [...]. É a arte de alguém, na verdade, drag queen é um ator. Ela monta todo esse personagem para transmitir uma mensagem. É uma coisa que aprendi aos poucos e hoje levo isso para mim, drag não é só bagunça, não é só um viado de peruca, não é só alguém engraçado na boate não! Olha se você olhar bem vai ver que ela tem uma mensagem por trás, é uma forma legítima de arte (Transcrição de entrevista realizada com Katy James no dia 22/06/2018).

Quando Katy James diz que drag "não é só bagunça, não é só viado de peruca”, ela não nega que "bagunça" pode constituir uma identidade drag, mas reitera uma noção de ativismo ao afirmar "tem uma mensagem por trás”. Ou seja, a constituição desse sujeito pode performar, dentro dos limites do "ser drag", o entretenimento e o ativismo, o hobbie e o "ser diva". Nesse sentido, a arte drag carrega aspectos que se

14 Disponível em: https://www.facebook.com/correiodoestado/ Acesso em: 27 de maio de 2019. 
interagem, um significado da arte drag não anula o outro. Sobre a ideia de ativismo drag, discutiremos mais adiante.

Há ainda interesses variados em relação a essa arte, como no caso de Stela Pink, que utilizou de sua intimidade com a moda para fazer um show em que mudava várias vezes de figurinos, pois a mesma faz seus figurinos e viu em sua drag uma opção para mostrá-los para outras pessoas, de ser reconhecida como designer de moda.

Trufada do Vrá, por sua vez, afirma que a drag não tem um gênero prédefinido, que ela pode ser quem ela quiser: "a drag queen não tem sexo ela não tem gênero, ela pode tanto ser homem quanto mulher, ela pode ser o que ela quiser, ela não tem limite".

No entanto, percebemos, com o referencial teórico utilizado até aqui, que a arte drag tem limites. Esses limites são dados pelo social, pelas relações de poder mediada socialmente. Como discutido, a agência dessas drags está condicionada por limitações que pode, até certo ponto, como afirma Neiva Furlin (2013), alterá-las, mas isso não quer dizer que a arte drag não tenha limites, pois eles são constituintes do sujeito. Por exemplo, as possibilidades delas têm como fronteira o inteligível. Vemos isso até na questão das referências que esses interlocutores tomam para as suas personagens, todas são mulheres ou drags que estão em destaque no cenário pop internacional e nacional. Ou seja, vemos que ao contrário do que Trufada do Vrá nos diz, a drag tem gênero, pois em nenhum momento alguma delas citou uma referência masculina para compor sua drag, ou alguém desconhecido do seu contexto cultural.

\section{Normas de gênero e performances drags}

A performance de gênero via teatralidade drag, como já abordada por Butler (1990) - que revela uma estrutura imitativa do próprio gênero - , demonstra que essas apresentações do evento se adequam não somente a categorias ou estilos, mas também se sujeitam a uma espécie de normativa do que seria mais aceito e bem-visto pelo público e quem as julga. Como, por exemplo, uma das apresentações que foi bem avaliada pelo público, no sentido de ter sido bastante ovacionada, foi o último show de Estrela da Luz, em que ela se vestiu como Cleópatra, dançando o estilo dança do ventre, carregada até o palco por homens sem camisa, performance bastante presente no imaginário de diferentes gerações via cinema, clipes musicais e shows de drag há algum tempo.

Chamamos a atenção em relação a essas e outras performances que são em/ pelos seus corpos que ocorrem as relações sociais de poder; neles é o lugar das intersecções, isto é, os consideramos os lócus de articulação de relações e legitimador de princípios sobre a sociedade (Monteiro, 2012). Pensando nesses corpos, podemos notar que as drags utilizam de sua corporalidade para fazer as suas performances. 
Esses corpos construídos e produtores de um processo de significação podem configurar as performances como as mais propícias para vencer ou não.

Por exemplo, no caso já citado de Rainbow, na boate na qual trabalha ela é conhecida como a drag barbada; na foto de divulgação do evento, Rainbow aparece toda maquiada, mas ainda barbada. No entanto, durante o evento ela tirou a barba para fazer sua apresentação, que foi definida por ela como uma apresentação "mais sexy, feminina e burlesque”. Quando questionada do porquê de ter tirado a barba, respondeu: "eu tirei para mudar um pouco e ficar mais sensual e tal, porque a barba não é muito aceita, digamos, poderia ser um ponto negativo no concurso e tal”. Quando perguntada do motivo pelo qual a barba não seria aceita, ela explicou: "porque, na maioria das vezes, elas querem que, tipo, todas sejam femininas e tal.. mas eu quero ser feminina com barba!”. Nesse sentido, como já foi discutido na seção anterior, esse fato reforça o quanto a agência delas é mediada pelo social, uma vez que, o concurso dita regras (também não escritas) em que elas devem se encaixar.

Durante o evento, Stela Pink, ao som de How to be a heartbreaker ${ }^{15}$, dançava, pulava, dava piruetas ao lado de um dançarino. Enquanto fazia tudo isso, trocava de figurinos de forma ensaiada como se nada pudesse dar errado. Sempre fazendo caras e bocas, ela interagia com a plateia, que gritava muito no sentido de aprovação. No final de tantas trocas de vestidos, ela ficou apenas com uma meia calça que nela estava colado corações que cobriam a genitália e os peitos. A performance dela se aproximou muito do feminino, mas ao mesmo tempo, se aproximava ao que ela desejava, que era o belo, o gracioso, o fazer as pessoas pensar sobre o tema feminilidade, pois, segundo ela, era essa a personalidade da drag, ela pensou a drag para ser uma princesa, uma protagonista, uma drag feminina graciosa, que usa roupas glamourosas. Ela afirmou ainda que busca ser firme na proposta da drag dela. Esse feminino glamouroso é um feminino que se assemelha à categoria top drag.

Segundo Vencato (2002), quando estudou a cena drag em Santa Catarina, a top drag seriam aquelas que têm posturas bem femininas, interagem com a moda, têm a obrigação de estarem bonitas e sexy, devendo se parecer um pouco com as mulheres top model. Chama a nossa atenção que essa categoria também foi mencionada nas conversas que tivemos com as interlocutoras. No entanto, o significado de top drag já não é mais o mesmo. Trufada do Vrá, como já dito, uma drag negra e gorda, é considerada por muitos como caricata por ser uma drag cômica, engraçada e exagerada, mas nos disse que se considerava uma top-drag. Hoje, uma nova geração de drags, diante do aumento do reconhecimento de top models gordas (plus size) e de outras mulheres igualmente midiáticas negras e/ ou gordas fazendo sucesso, estão se autodefinindo como tais e se considerando como top.

Já a apresentação de Estrela da Luz buscou um caráter mais impactante: com o uso de adereços, ela representou a dama da justiça, toda de branco, relembrando o

15 Em tradução livre “Como ser uma destruidora de corações". O clipe da música é com vários homens tomando banho de sunga. Clipe disponível em: https://www.youtube.com/watch?v=vKNcuTWzTVw. Acesso em: o1 de jun. de 2019. 
caso da travesti Dandara dos Santos, de 42 anos, morta, apedrejada e a tiros no Ceará, em 15 de fevereiro de $2017^{16}$. Ela iniciou a sua apresentação com as luzes apagadas e uma fala sobre lgbtfobia. Após o texto falado, quando as luzes acenderam, ela surgiu como dama da justiça, com uma balança nas mãos, com o rosto coberto, ao som de Angel by the wings ${ }^{17}$, da cantora australiana Sia, fazendo gestos com as mãos de modo a aparecer que estava triste. Assim que ela tirou a máscara que cobria seu rosto, foi possível notar que ele estava coberto por sangue artificial. Além disso, usava lentes de contato que fizeram seus olhos parecerem estar todos brancos, surpreendendo a plateia. Ela tirou aos poucos toda a sua roupa branca, mostrando assim seus peitos cobertos de sangue (uma espécie de prótese de plástico que dava realismo a cena). Atrás dela, levantam a bandeira com as cores do arco-íris do movimento LGBT. Nesse momento, ela teve a cabeça raspada durante a apresentação. A plateia, chocada e emocionada, assistiu ao show muito atenta. Quando terminou a música, uma amiga que foi convidada por ela, fala da história de Dandara. Esta amiga, que é transexual, interpreta Dandara. Quando chega no final da apresentação, a amiga é carregada no bar em um carrinho de mão - como ocorrido com Dandara antes de ser assassinada - até o palco, onde foi jogada.

A performance de Estrela da Luz nos chamou a atenção pelo fato de explicitar elementos que subsidiariam a sua apresentação como artivismo, afinal, autores tem citado “a expressão ‘artivismo’ para tratar de artistas que usam a arte como maneira combativa, com fins políticos” (Thurler et al. 217: 25).

No entanto, quando questionada se ela tinha feito artivismo em sua apresentação, ela disse que não. Estrela da Luz não sabia o que significava essa categoria. Quando foi explicado, ela disse que até que sua apresentação poderia se encaixar em artivismo, mas ela não realizou essa apresentação com o intuito apenas de realizar um ato ativista, mas afirmou e reafirmou que pensou nessa performance para chocar o público e, com isso, ganhar o concurso. Ela diz que ficou muitos dias se preparando e ensaiando para que nada desse errado, para que tudo tivesse "um encaixe na música". Toda a sua performance foi pensada em cada detalhe para prender a atenção do público.

Assim, mesmoquea apresentação delaten ha consistido num questionamento das normas, ela encontrou no corpo da Dandara uma forma para sensibilizar a plateia. Ao fazer isso, ela revela que sua performance se sujeita a outras normas/ interesse do que seria valorizado pelo público da Corrida. A performance como tal, produziu um efeito político no público de forma intencional, contudo, o seu real interesse não tinha necessariamente um aspecto de militância, mas de ganhar o concurso.

16 Informações sobre o caso, disponíveis em: <https://g1.globo.com/ce/ceara/noticia/cinco-dosacusados-pela-morte-da-travesti-dandara-sao-condenados.ghtml>. Acesso em: 22 de abr. 2019.

17 em tradução livre "Anjo Pelas Asas", melodia triste e tem em seu refrão a repetida frase "você pode fazer qualquer coisa" 
Trufada do Vrá também trouxe na sua apresentação um caráter ativista. Ao som da música Não Recomendado ${ }^{18}$, de Caio Prado, ela vestia uma capa preta, maquiagem impecável e cabelos presos - cabelos estes que são "naturais", isto é, alisados; não usava peruca ou aplique. Em um certo momento da música, ela retira essa capa, e vimos que ela está apenas com um short, e com algumas placas coladas nela que diziam: "gordo", "censurado", "afeminado" e "viado" (todas no masculino). A plateia, nesse momento, vai à loucura, aplaude e grita muito, também no sentido de aprovação daquela performance que estava acontecendo ali.

Aquele corpo que está sendo apresentado, para a Trufada do Vrá, subverte a ordem de ser drag, pois ela se distingue das outras drags por ser a única drag gorda, e uma das únicas negras da competição. Deste modo, o desejo de se montar e se apresentar como top drag constitui a agência a sua performance como uma prática de articulação e de ressignificação, sendo um atributo de resistência ao que está sendo visto como aceitável dentro dos códigos de significação drag. Esse desejo de se impor ao padrão, mesmo utilizando uma categoria historicamente reveladora de padrões diferentes dos seus (a de top drag), produz novos efeitos nesse contexto, ou seja, é uma ação transformadora, gerando uma possibilidade de resistência (Furlin, 2013). Isso não se trata de uma libertação das normas, antes, de uma possibilidade de subversão contextual desses padrões.

Assim como Estrela da Luz, Trufada do Vrá, quando questionada sobre se aquela apresentação seria uma forma de artivismo, disse que aquela apresentação foi ativista, mas que ela geralmente faz mais shows de bate cabelo ${ }^{19}$, porque o público dela gosta mais. Ela diz que aprendeu a militar. Esse aprendizado veio a partir de uma outra drag, que lhe serviu como inspiração, isto é, a primeira ganhadora da "Corrida das Drags", em Campo Grande. Essa referência, mesmo em tempos de mídias sociais em que a imagem das drags são conhecidas e difundidas em redes transnacionais, é local. Isso mostra o quanto a questão da circulação das imagens não ocupa o espaço das relações off-line, das experiências locais de montagem. Segundo ela:

A Gisela Popovic que me inspirou fazer esse show, ela que fez um show desse na verdade. Eu falei para ela assim: "vou pegar seu show como inspiração". Só que foi bom porque ela também é gordinha, também é afeminado e também é viado. Na hora que eu fiz o meu show eu senti o peso do impacto só pela minha cor. [...] senti que emocionei o povo. Fazer a arte drag é uma forma de militância, estamos militando de qualquer forma (Transcrição de entrevista realizada com Trufada Do Vrá no dia 13/08/2018).

18 Esta música foi eleita o hino do movimento LGBT no Brasil em 2017. Como disse o blog Malaguetas, foi cantada por outros cantores que representa o movimento LGBT: Liniker, cantora negra, pobre e LGBT, cantou essa música juntamente com Johnny Hooker, no Rock in rio 2017. Fonte: http://malaguetas. blog.br/nao-recomendado/. Acessado em 20 de nov. de 2018.

19 Momento do show em que uma drag queen é cheia de energia e adrenalina e começa a girar sua cabeça freneticamente, transmitindo sua energia para o público, as pessoas gritam e aplaudem sem parar. Disponível em https://www.dicionarioinformal.com.br/bate-cabelo/ Acessado em 11 de nov. de 2018 
Nota-se que Trufada se inspirou em uma drag para realizar o seu ativismo, considerando esse show "bapho" para ela levar para o concurso; assim, ela revela uma imitação de outra drag, indicando desta maneira a paródia da estrutura imitativa de gênero nos termos aqui complexificado, como já discutido. No entanto, o fator raça aparece em destaque, inesperadamente, sob a sua avaliação, que, diante do público, ganha um "peso".

Deste modo, mesmo quando os elementos que caracterizaria as apresentações como artivistas estão presentes, esta categoria era desconhecida por elas, ou seja, na visão das interlocutoras, no evento, esse movimento teorizado por Colling, Thurler, Trói e Garcia (2017), não se faz presente na realidade sul-mato-grossense analisada aqui.

Outro ponto que pode ser e discutido é o fato dessas drags não representarem a todo momento a intenção de subverter normas de gênero. Como Butler (2003) afirma, nem toda paródia é subversiva. Por isso, Trufada do Vrá, no que se refere a militância, pode ter a seguinte compreensão problematizada "[...] estamos militando de qualquer forma”. Ou seja, as drags não necessariamente vão questionar as normas, elas podem também as reafirmar.

No entanto, mesmo sem o questionamento intencional destas mesmas normas, para elas, as apresentações drags já representam por si só uma forma de tensionamento, visto que desafiam a expectativa da norma por serem corpos com pênis apresentando-se como femininos.

\section{Conclusão}

Retomando o objetivo deste artigo, pudemos analisar a configuração da performance drag diante de uma sociedade que regula corpos de acordo com suas normas em contexto sul-mato-grossense. Essas performances se dão em um evento "Corrida das Drags" foi visto como algo alternativo em relação aos outros eventos na cidade, ainda que alguns desejassem que ele tivesse sido realizado em um local mais valorizado. Além disso, a sua importância para quem se envolveu é como a do futebol para o público de homens heterossexuais, corroborando o quanto um outro normativo ajuda uma de nossas interlocutoras a nos explicar o valor das experiências etnografadas. Para além dessas constatações, esse evento trouxe reflexões e análises importantes a respeito da diferenciação identitária valorativa entre travestis e drags, algo que tem tido certa continuidade histórica, isto é, que demarca mais que uma geração. Diferenciação essa que se dá em meio a valores altamente normativos que constituem fronteiras identitárias que passam pela performance do corpo nessas distintas experiências de ser ou não travesti.

Podemos ainda considerar que a performance drag tem se complexificado, em especial quando analisada via teoria butleriana, visto que, diferentemente do que foi apontado anteriormente, essa nova geração tem tomado como referência para 
a performance e montagem outra drag, não somente a mulher. Além disso, ainda que para as interlocutoras o "ser drag" não tenha limites, para além dos interesses pessoais, elas precisam negociar/agenciar, em meio às exigências normativas, as suas apresentações nesse contexto competitivo.

Contudo, isso não significa que exista apenas reiterações, afinal, como discutido, o reconhecimento de perfis de feminilidades diferentes do então corpo branco e magro, permite novas experiências drag serem assumidas como top. Mas, ainda que as apresentações de algumas tenham tido um teor "militante" ou "ativista", o interesse das mesmas não era a transformação ou crítica social, antes, "ganhar a Corrida". Para isso, participaram do evento nos possibilitando pensar, em certa medida, o corpo como o espaço das relações sociais, em temporalidades e corporalidades drags frutos do nosso tempo.

\section{Referências}

REVISTA CULT. (2017). São Paulo. Artivismo das dissidências sexuais e de gênero, v. 226.

BRAH, Avtar. (2006). Diferença, diversidade, diferenciação. Cadernos Pagu, n. 26, p.329-376, janeiro-junho

BUTLER, Judith. (2003). Problemas de gênero: feminismo e subversão da realidade. Rio de Janeiro: Civilização Brasileira.

CHIDIAC, Maria Teresa Vargas. OLTRAMARI, Leandro Castro2004). Ser e estar drag queen: um estudo sobre a configuração da identidade queer. Estudos de Psicologia, p.471-478,

COLLING, Leandro. (2016). Dissidências sexuais e de Gênero. Salvador: EDUFBA.

DUQUE, Tiago. (2017). Gêneros incríveis: um estudo sócio-antropológico sobre as experiências de (não) passar por homem e/ou mulher. Campo Grande, MS: Ed. UFMS,

DUQUE, Tiago. (2011). Montagens e Desmontagem: desejo, estigma e vergonha entre travestis adolescentes. São Paulo: Annablume.

FURLIN, Neiva. (2013). Sujeito eagência no pensamento de Judith Butler: contribuições para a teoria social. Sociologia e Cultura, Goiânia, v.16, n.2, p. 395-403, jul. -dez.

GREEN, James. (200o). Além do carnaval: a homossexualidade masculina no Brasil do século XX. São Paulo: Editora UNESP. 
MAGNANI, José Guilherme Cantor. (2009). Etnografia como prática e experiência. Horizontes Antropológicos, Porto Alegre, ano 15, n. 32, p. 129-156, jul.-dez.

MISKOLCI, Richard. (2009). A teoria queer e a sociologia: o desafio de uma analítica da normalização. Sociologias, Porto Alegre, ano 11, no 21, p. 150-182, jan.-jun.

MISKOLCI, Richard. PELÚCIO, Larissa (2007). Fora do Sujeito e fora do lugar: reflexões sobre performatividade a partir de uma etnografia entre travestis. Gênero, Niterói, v.7, n.2, p.257-269.

MONTEIRO, Marco Synésio Alves. (2012). Os dilemas do humano: reiventando o corpo em uma era (bio)tecnológica. São Paulo: Annablume,

PELÚCIO, Larissa. (2012). Subalterno quem, cara pálida? Apontamentos às margens sobre pós-colonialismos, feminismos e estudos queer. Contemporânea, v. 2, n. 2 p. 395-418 jul.-dez.

PISCITELLI, Adriana. (2008). Interseccionalidades, categorias de articulação e experiências de migrantes brasileiras. Sociedade e Cultura, v.11, n.2, p.263-274, juldez.

SILVA, Helio R. S. (1993). Travesti: a invenção do feminino. Rio de Janeiro: RelumeDumará: ISER.

TREVISAN, João S. (2004). Devassos no paraíso: a homossexualidade no Brasil, da colônia à atualidade. Rio de Janeiro, São Paulo: Record.

VENCATO, Ana Paula. (2002). "Fervendo com as drags": corporalidades e performances de drag queens em territórios gays da Ilha de Santa Catarina. Dissertação (Mestrado em antropologia social): Programa de pós graduação em Antropologia Social, departamento de Antropologia Social do Centro de Filosofia e Ciências Humanas da Universidade Federal de Santa Catarina. Florianópolis.

Recebido em 21/11/2019.

Aceito em 08/11/2020. 